\title{
THE ANALYSIS OF ENVIRONMENTAL EFFECTS ON THE DESIGN AND PRODUCTION OF ARTS IN USE, BASED ON PRINCIPLES OF HUMAN GEOGRAPHY (CASE STUDY: IRANIAN CARPET)
}

\author{
Majidreza Moghanipoor \\ $\mathrm{PhD}$ student of Art Research, Faculty of Art,Shahed University, Tehran, Iran \\ Mohsen Marasy \\ Professor Assistant,Faculty of Art, Shahed University, Tehran, Iran \\ marasy@shahed.ac.ir
}

\begin{abstract}
The main topic of this article is recognition and analysis of influences of "Arts in use", as a human phenomenon (from a geographical viewpoint) and one of physical manifestations of culture ( from the environmental viewpoint). Accordingly, opinions and concepts related to this issue have been analyzed in the field of human geography science by an interdisciplinary approach and a descriptive-analytical methodology. Therefore, an "Iranian carpet" as a centerpiece of these studies divided into the processing (production manner), forming (aesthetic) and technical (in practice) components, then, was studied the affecting manner of each of these components by the environment. By conducted reviews and analyzes, one could say that proposed discussions in the schools and classic theories of environmental determinism and the possibility thinking (from the field of human geography) has the same line with suggested definitions for "style" and "school" in the field of carpet studies. As a result, in the areas where become prevalent carpet-weaving styles, environmental and geographical circumstances has a more highlighted effect on the conditions of the production process and quality of the final product; but in the areas where producers styles or technique of carpet designers are applied, it is more evident the human hegemony over the environment
\end{abstract}

Keywords: Iranian carpet, Environmental determinism, Possibility thinking, Culture, Style

\section{INTRODUCTION}

The use of methods and approaches of different sciences for analyzing one topic causes continuity of a business pattern and the increase in effectiveness. In fact, using the various specialized disciplines for studying one topic, produce a modern knowledge system. (Faramarz Gharamaleki, 1380:253), viewing the phenomenon, supplementation, interference and integration in certain fields are parts of interdisciplinary studies objectives in the field of Humanities; this means that specialized disciplines more or less need to become aware of quantity and quality of the connected fields for benefiting from a more comprehensive viewpoint and consequently for avoiding one-dimensional perception of the phenomenon. (Ebrahimi, 2014: 25) this approach has a structure fertilized from different disciplines which produce a larger extent of understanding. (Rostami, 2015: 64), this study type, not only accept other viewpoints, but also it needs to a serious and systematic encounter with them, it benefit from different viewpoints with avoiding exclusivism of methodology. (Faramarz Gharamaleki, 1380:253) thus, in the recent years, we could see a more serious presence of interdisciplinary approaches like art sociology, art psychology, art economy, art anthropology and etc. in the art investigations. In this paper, by searching theoretical common characteristics of the art (particularly, arts in use) and the human geography, we intend to take an action for making more rich the theoretical principles and frameworks of researches or studies of the art which suffers greatly from a lack of investigation. 


\section{RESEARCH METHOD}

By an interdisciplinary approach and descriptive-analytical methodology, this paper seeks to explain nature and reason of some aspects of Iranian carpet as one of arts in use. According to this purpose, at first we introduce the proposed theories in important geographical schools in which has been analyzed the affecting manner of human societies by the nature in different ways, also we analyze keywords like phenomenon, landscape, environment and culture in order to achieve a more systematic and more accurate understanding of the present topic; in this part, the position of carpet becomes clear as a physical manifestations of the culture for explaining this concept. In the next, we also introduce the forming character (aesthetic), technical (in practice) and the processing dimensions of a carpet. Then, we analyze types of environmental effects on these dimensions in a qualitative way.

\section{RESEARCH BACKGROUND}

The affecting different dimensions of culture and art, is the study subject and body of the geography branches which publish specialized studies and theories under the heading human and cultural geography. Kavyani Nejad (2004) suggested a research under the heading "Geographical foundations of the Iranian culture" in which the author investigate how the emergence of the cultures different from the environment; this research, from "possibilism" and "determinism" viewpoints, has been studied environmental effects on different physical and spiritual manifestations of culture of human societies, It also has been analyzed the effect of environment and geographical position on Iranian carpet. Pope in his series of investigations of Iranian art, in an article under the heading "The relationship between geography and art in Iran", conclude that natural conditions of environment is a developer or neutralizer factor of effective thoughts on art. He has been explained this topic regarding distribution and expansion of Islamic art in Iran. Also, other articles and researches in a more direct way, has been studied the effect of environmental conditions on art or architecture as follow: "the effect of environmental factors on building and decoration pattern of rural houses"(Ghazanfarpour, Kamandari, Mohammadi Soleimani, 2012), "Geography and Art" (Shokouhi, 1996), "Component of geomorphology and its effect on ty particularity and art of Iranian handmade carpet" (Baba Jamali). Tooraj Zhouleh, one of researchers, was linked concept of the carpet style with environmental conditions, culture and lifestyle dependent on it. .

\section{The effect of environment on culture}

There are two important viewpoints in Geography science regarding the effect of environment on custom and culture, one is known as "Environmental determinism" and other is called "Possibilism"(powers thinkings). One might say that next viewpoints of this science typically are continuity and integration of these two viewpoints. One could analyze interaction of human \& environment, and formation of culture arising from this interaction within the framework of these two schools (Kavyani Rad, 2004:88).

\section{A-environmental determinism}

geographical or environmental determinism is one of important intellectual traditions in the field of classic ecology and accordingly, the physical (natural) environment is a main impellent of human affairs, it includes character, survival, death, government, religion, physical and spiritual culture; according to this viewpoint, natural conditions are certain and determinative factors of human events and geographical phenomenon. Ratzel, German geographer (1844-1904), was a pioneer of determinism in human geography (Farid, 1991:4), he intended to establish a correlation between natural sciences and human sciences so that by this way, an academic method use for studying human sciences. Ratzel in first edition of his book: "The geography of Anthropology" put a lot of emphasis on the impact of natural conditions of the planet on human culture. (Beyg Mohammadi, 1377: 15), later on, his theory developed by his disciples and covered all parts of human culture. (Shokouhi,1996:29), among the scholars of the Islamic cultural sphere, "Ibn Khaldun" based on the division of an occupied or inhabited part of the earth into seven climates for each of them determines specific natural and human characteristics which are results of the geographic and climatic factors governing them. He says that geographic conditions are effective on 
the formation of civilizations, quality of religious beliefs, intellectual power, physical situation, morality and behavior of human and he accept a kind of environmental determinism (Hafeznia, 1996:55).

Until the early twentieth century, thoughts of environmental determinism prevailed over the geographers and other thinkers. In this context, they also tried to understand the changes and differences in cultural atmosphere, by realizing a mutual relationship between human and natural environment. But, along with scientific, technical and cultural advancements of human societies in the early twentieth century, it was more important the role of human in geographic and cultural studies. Thus, by a cultural approach, some geographers criticize dominant ecological paradigm, namely, natural environment determinism and view human beings as "intelligent and capable players" who assume the responsibility for producing space and place in their social life and appear in the environment with their political and social ideas. These thoughts ultimately led to develop possibilism theories and the emergence of geo-cultural branch of geographical knowledge (Kavyani Rad, 2004:89).

B-possibilism: In the first half of the twentieth century, Vidal dela Blache discussed the possibilism of relationship between human and the natural environment, by criticizing one linearity of geographic determinism approach. In his opinion, the geography was a science of places; a main centerpiece of his though was confirmation of lifestyles in different geographical places. Accordingly, a change in values and attitudes could lead to further utilization from facilities or adequate facilities put at the disposal of human societies. (Shokouhi, 1996:30): possibilism is a philosophical viewpoint in which the natural environment, provide facilities for human choice until he choose them in accordance with his cultural needs in life. This viewpoint is in agreement with free choice of human, not his limitation. Therefore, based on place-space pattern, activities and behavior of human is formed in the free environment. (Shokouhi, 1996:32) a main centerpiece of Vidal dela Blache though was confirmation of lifestyles that has been developed in different geographical places. In his opinion, a change in values and attitudes could lead to further utilization from facilities or adequate facilities put at the disposal of human societies. (Behforouz, 1995:18) therefore, an absolute determinism is not valid in Geography, then anything which may relate to human is a possible thing and a natural obstacle is Passable and penetrable in the realm of possibilities. (Kavyani Rad, 2004:90) according to authority supporters, humans are main producers of culture, not natural environment. Local features of culture and economy is an outcome of cultural decisions which is chosen according to the facilities arising from the natural environment. This feature is shown on the concept of "cultural adaptation" in an attractive manner.

\section{Explanation of concepts of human geography and the range associated with them}

In this part, given the importance of the concepts related to science of human geography, we analyze more accurately outstanding concepts like: "phenomenon", "environment", "Landscape" and "culture", even though in some of these subcategories, were also seen the conceptual overlapping.

A phenomenon is any event or topic that is produced in the space of human life and is perceived through his senses. Development of "phenomenon" concept has a direct relationship with the possibilism thoughts; therefore, the existence of geographic phenomena is formed by causal relationships, the earth and human mutual affecting. (Jordan and Rowntree, 2001:5) phenomenon or geographical phenomenon considering the kind and origin, divide into "natural phenomena" and "human phenomena". Natural phenomena are made by natural causes, so humans and his culture has no role in making them; these phenomena, essentially, are created by integration and interplays of natural elements that play their role within a causal system like: climate, landforms, rivers, seas and lakes, soil, vegetation, animal coverings and etc. On the other hand, human phenomena produces by human activity on the way to interference natural environment and establish a hegemony or coexistence, human phenomena are as follow: country, city, village, farm, garden, path, domestic animals and etc. All these phenomena are outcome of a collision and interaction between human and nature. (Plume Wood, 2002: 26). 
The environment in Geography is a set of elements that enclose the establishment point of a phenomenon and its surroundings; therefore, according to the type of components that make environment of any phenomena (Which may be natural or human) they are different in nature and provide distinctive potential. As usual, environments essentially divide into four categories: natural, geographic, and perceptual and in use. (Badri far, 2011: 16) the natural environment has been made by an integration and interplay of natural elements, and human was started their activities based on this level. The quality of natural environment as a context of human societies arises from absolute and relative twofold positions of that environment. An absolute position is measured based on latitude and longitude and have a system (degrees, minutes and seconds). Specific latitudes and longitudes have a certain range of climates on the earth. In the relative position (natural environment), areas and environments are evaluated in comparison to each other (from natural, human and cultural viewpoint) and are measured based on the level and depth of their interactions (Kavyani Rad, 2004: 85).

By adding human and his activities to natural environment, in other words, by starting interference of human beings in nature, geographical environment change to natural environment. (Badri far, 2010: 17) the knowledge that Humans obtain from features of the natural environment through their realization is known as perceptual environment. In other words, perceptual environment is an atmosphere that is formed in the minds of people through information and knowledge of individuals \& society. the human understanding of the environment is directly linked to their culture and general information about the nature; the environment that is used by all utilization systems including agriculture, animal husbandry, production, services and etc. and its inhabitants continue to their living by the use of their selective ways is known as practical environment. Utilization systems and living ways and in fact, enjoying the environment has a relationship with human societies understanding of the environment, namely, " the environmental perceptions" as well as the existing facilities in it (BehForouz, 1995:27).

Geographical landscape is a certain space created by interaction of various natural and human forces in a certain spatial context. (Sokouhi, 1996:14) one could examine geographical landscape in two forms: "natural landscape" and "cultural landscape", in other words, one could analyze a geographical landscape based on type and manner of relationships between human and natural elements. While a natural landscape focus on natural aspects of a location such as climate, soil, mineral resources and reserves and etc. it has a potential effect on formation of human life. A cultural landscape is often a set of human actions in one place and over time (Keren, 1983: 37). This landscape reflects an interaction manner between human culture and natural environment in one place and over time (Jordan and Rowntree, 1380: 43). 

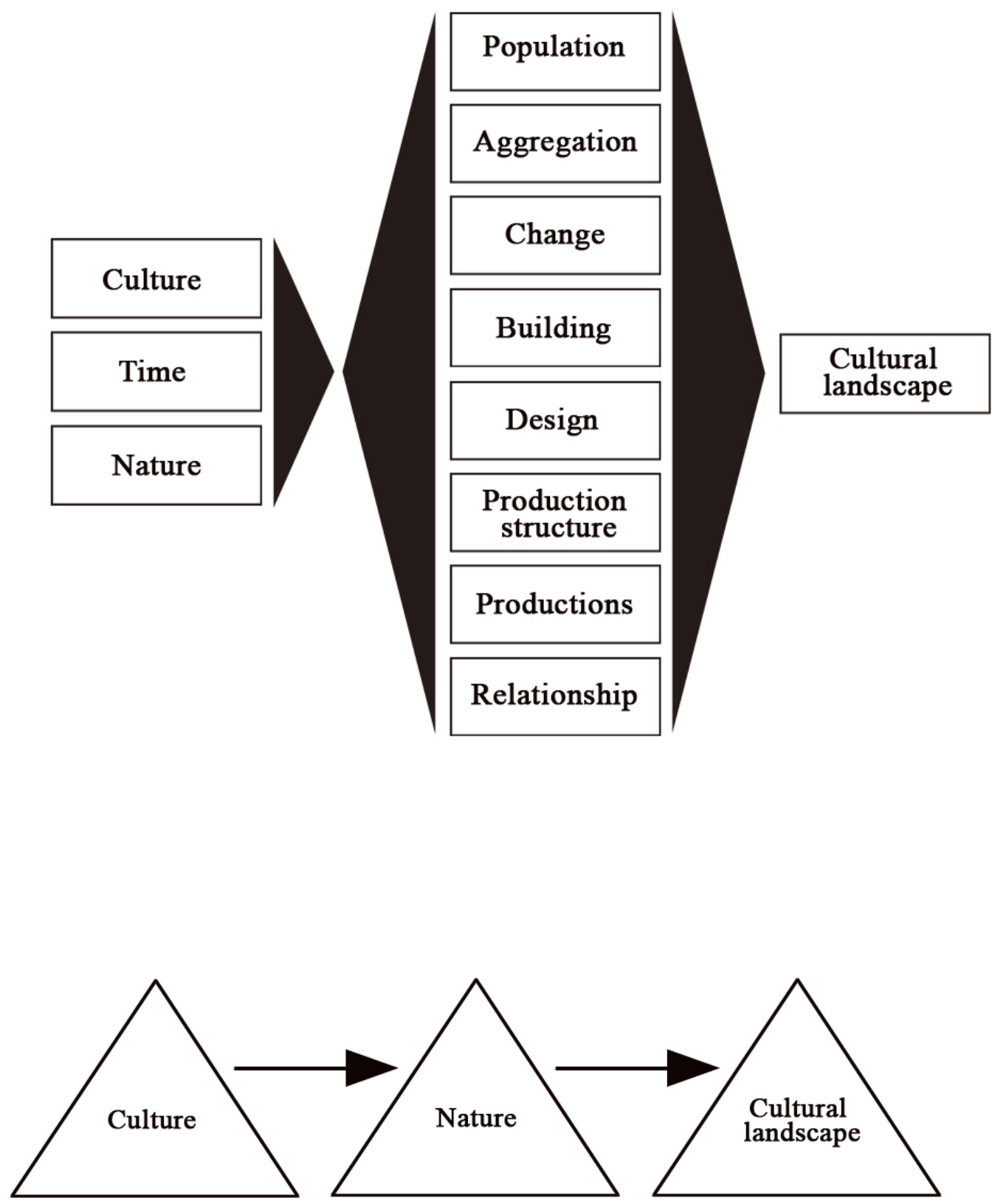

Figures 1 \& 2: Relationship between Culture, Nature and Cultural landscape

By a brief look at the components and concepts like environment, phenomenon, and landscape, is clear their deep connection with the concept of "culture", particularly in the study of human geography. Therefore, "culture" is one of key concepts in such studies. Fokouhi in his book: "Principles of an anthropology" has been provided an applied definition of culture, he has defined culture in its most general form: it is almost a coherent set and an integration of attributed and acquired phenomena in intellectual and behavioral contexts which are common and accepted at a certain time or place and in a specific society and it is transferred from one generation to another". (Fokouhi: 1392) in general, culture includes two types of phenomena: "behavioral or physical" and "intellectual or spiritual". The physical 
culture is directly recognizable by one of our senses; objects are simplest forms of physical culture. Also, the art is one of the most obvious forms of physical culture. On the other hand, spiritual culture is not recognizable by our senses, human could understand this type of culture only through its change to physical culture in a complete or partial, permanent or temporary form; any element of physical culture can be infinitely remained in the material forms. Also, these two cultural components are almost inseparable from each other (Fokouhi, 2008).

\section{Iranian carpet}

Forms and cultural \& geographical affecting are displayed in a different way in the arts that are develop and received in the real social space; an obvious example of these works category, are known as "Arts in use" (opposite the Fine Arts). There are various and effective characteristics like performance, economy, geography, culture, society and belief in developing and receiving process of these arts that analysis of relationship between "human / environment" make more sophisticated and different from cause and effect patterns of other human behaviors and phenomena. These effects and arts are created in their historical and geographical range in different ways and each form or way demonstrate environmental, cultural and natural contexts of these effects. Iranian carpet has a specific importance and validity among applied arts due to extensive variety of production and also a rich history in different geographical fields, so that in development period of this art-industry, has been identified over three hundred active region of carpet weaving that every area had produced this carpet in their certain ways, characteristics and rules, this geographical diversity of the product has led to create character diversity in Iranian carpets (Saravi, 2004).

\section{The concepts of style and school in understanding the carpet}

there are many perfect definitions of "style" and "school" in the field of art, according to the use of these words in the field of fine arts, some researchers are explained "style" and "school" (in the art, including carpet) as follow: "the art style, is a kind of method and procedure that in an artistic field, is developed by an artist for the first time and gradually, this method is used by others and is practiced and completed in their works, in this case, the artist use similar structure, form and context in his works and thus an artistic style improve to an artistic school ... "(Daryayi, 2008:42). But, it seems this sense of style and school for a work like carpet is a minimalist explanation, because when we review and analyze mood and functional requirements of Iranian carpets, It becomes clear that many of the components and factors affecting the character of a carpet (forming and technical) has not been observed in these definitions. Therefore, some researchers have tried to provide a more adaptive definition of these concepts by a more perfect understanding of mood and functional requirements of Iranian carpets in its geographic and historic extent. According to this, Tooraj Zhooleh in the field of carpet study has defined "style" as follow: "the inner and outer specific structure of a carpet, affected by a collection of environmental, geographical and native causes and factors that causes a product has unique features and to be distinct from other carpets, both physical and inner aspects." In this way, the taste and desire of an artist, designer or weaver consider as a last effective factor in the formation of a style, and before anything, all preliminaries of its formation are affected by environmental causes "(Zhooleh, 2013). Generally, in the initial state, one could categorize dominant styles of Iranian carpet into three types: urban, rural and nomadic. (Hangldin, 1996: $9)$ it is the result of interactions and relations between man and environment. Obviously, If for any reason, the weaver or designer leave behind environmental, climatic and indigenous causes and his tastes and interests of the customer overcome the inner and outer structure of in the selection of designs and colors, row number, elegance, size and ..., carpet style will disappear. In other words, school of designers and weavers will overcome the native and local styles of each region. Thus, in the definition of school concept in the carpet study, one could say that "it is a reflection of the technical and artistic features of a designer, weaver or producer including the teachings, tendencies and individual interests that the inner and outer structure of the carpet, in particular design and color, is greatly id by it." Investigation of Iranian carpets schools has two independent branches which includes scnours of artists and schools of weavers and producers (Zhooleh, 2013: 19-20). 


\section{Environmental influences of Iranian carpet}

The study of carpet-weaving history and the outer and inner differentiations of various types of Iranian carpets in its limitless geographic range reveals that understanding differences of cultural and geographical contexts of production, is one of the most important ways for identifying Iranian carpet; affecting "Iranian carpet" by the environment, could be examined based on two centerpieces: first, effect of these conditions on production processing dimensions (production facilities, production arratam, production time), second, shaping type of environmental conditions of one area to "forming/ ae and "technical/in practice" dimensions of carpet of that area.

The production process could be influenced by the geographical conditions from three viewpoints production facilities, production systems and production time. Production facilities means the availability of natural and human causes and factors for the formation of a carpet is in a particular geographical area. There are lands with favorable amphibious conditions that provide adequate plant coverage for the formation of livestock pastures and these cattle produce the main raw material of carpet. Also in the areas where is a thriving agriculture And somehow in an interaction between human and nature, the nature has more hegemony over human, more people (mostly women and girls) involved in the production process; on the contrary, this phenomenon is shown in industrial areas where in the interaction of nature and humans, human display a more powerful presence. An important point is that in the geographical environment where is no agricultural and industrial, we can see numerous men in the field of carpet weaving.

The carpet production system in Iran divide into two centralized (or workshop) and decentralized (or household) categories, obviously, a nomadic lifestyle that is affected by environmental conditions, ke no possible a centralized manufacturing this product. According to this, when we travel to rural areas and subsequently to the city, we can see the centralized production system. In other words, in the interactions and relations between human and nature in a geographical environment, when the presence of natural causes and phenomena are highlighted, the system of manufacturing products such as carpet is shown as a single and domestic one. And with the dominance of human factors and phenomena, the production system change to more centralized and more organized form. Also, In areas where based on the environmental conditions, men have more highlighted presence in manufacturing this product, we see more centralized carpet-weaving workshops (as a base for a permanent profession); we can refer to different cities of Razavi Khorasan as excellent examples of these areas in Iran. The topic of more production time is discussed in areas where climatic conditions, produce a thriving agriculture, normally in these environments, taking part in professions such as seasonal carpet-weaving is carried out when finish the main profession (agriculture).

However, products such as carpet, has most impressions in their forming (aesthetic) and technical (in practice) features; in Figure 3 is displayed an example of these influences: 


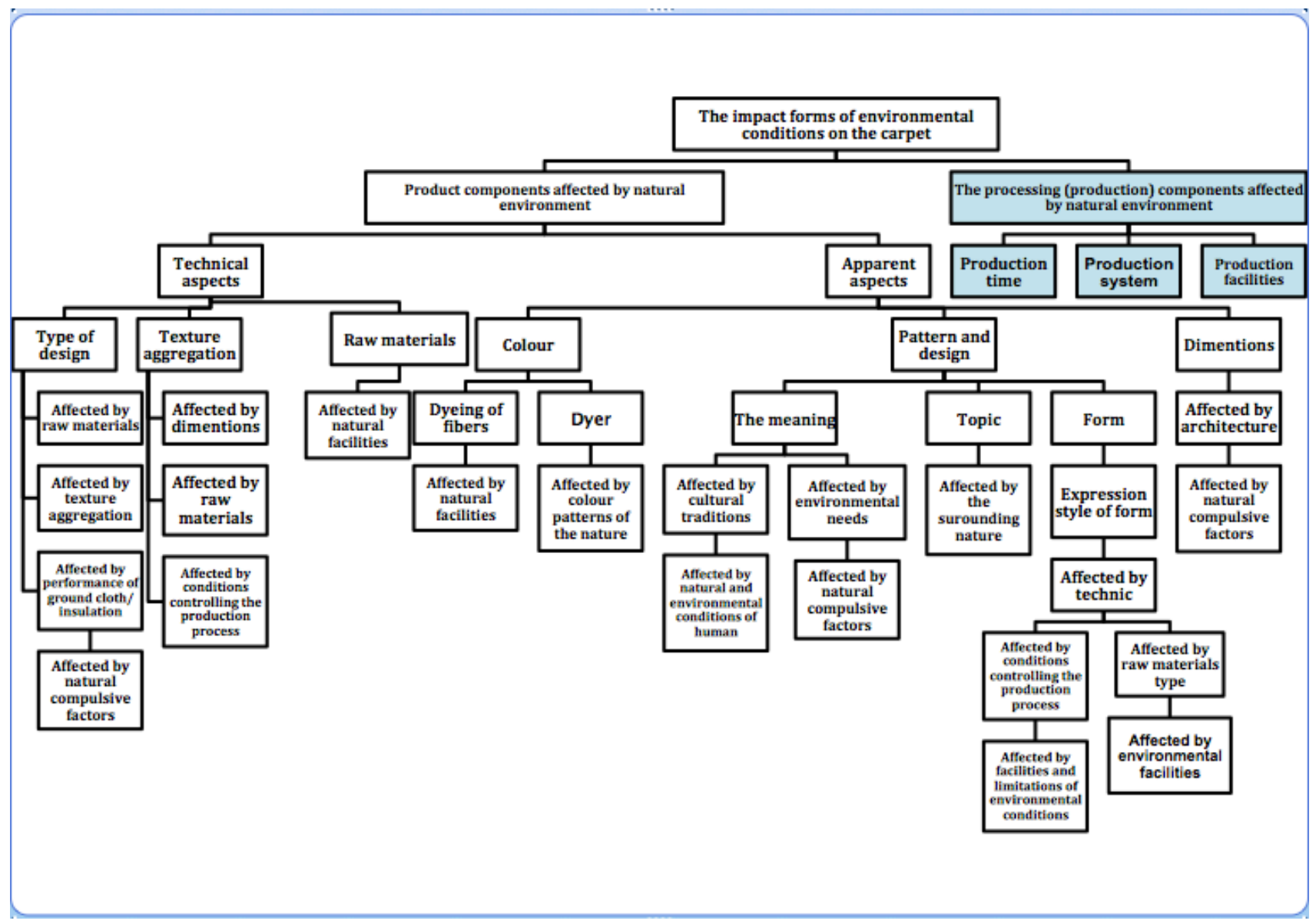

Figures 3: The Impact Forms of Environmental Conditions on the Carpet

As one could see, many outstanding components of a carpet, is somehow affected by the surrounding natural environment; for example, dimensions of a carpet with regard to its performance that is used as a flooring for residential areas, is affected by the dimensions of architecture internal space. On the other hand, self- architecture of an area as one of the first and perhaps the most important cultural manifestations -which provides a specific cultural landscape for a natural location- is affected by environmental conditions of that area. Introversion and extroversion of an architectural space, determines the different sizes of the room, so that in cold regions, the size of rooms is smaller, but in the tropical and central regions of Iran, the situation has changed. This leave a direct impression on the size of produced carpets. Also in cold regions where carpets in addition to cover the indoor, has an insulating function, usually, naps tallness (a sequence of nodes) is higher. Because the elegance of design and pattern is not very clear in these conditions (being tall nodes), carpets are woven with relatively low aggregation, this issue and texture mechanisms of each area causes designs on carpet appears in half-rotating and damaged forms.

But, the main point of this article is lack of affecting many areas by the determinism conditions of environment for manufacturing products such as carpet; for example, in large and cold cities such as Tabriz and Mashhad where incidentally are considered as main centers of carpet production, there is a situation different from what was described, so that the sizes, aggregation, motifs and designs does not follow the environmental conditions. To illustrate this issue, we should look at the topics presented in previous parts of this paper. When we discussed "possibilism" and "determinism" schools, and interactions and relationships between human and the natural environment, we found the main difference 
in the power of one and other inability. according to this, "determinism" schools emphasized the human inability when encounter with the nature, they said that all thoughts and practices of human are influenced by the environmental determinism; On the other hand, possibilism supporters believed that the human triumph over this confrontation and by his authority overcome any circumstances and environmental factors has no effect on his power.

In a phenomenon like the carpet, one could conform these two approaches to definitions of "style" and "school" in this field. As a result, in the areas where become prevalent carpet-weaving styles, environmental and geographical circumstances has a more highlighted effect on the conditions of the production process and quality of the final product; for example, the nomadic products is more affected by the nature of immigrant areas. Also, in the areas where producers styles or technique of carpet designers are applied, it is more evident the human hegemony over the environment. for example, in the products were made in urban schools like: Tabriz, Isfahan, Mashhad, Kerman and Kashan, one could see less direct affecting by natural environment.

\section{CONCLUSION}

A complex nature of human and the inability of a certain field for understanding and explaining all human phenomena including artifacts, make clear the necessity of multidisciplinary studies more than ever. In this paper, we tried to search theoretical common characteristics of the art (particularly, arts in use) and the human geography for making more rich the theoretical principles and frameworks of researches or studies of the art. Thoughts, opinions and activities of human societies always become manifest on the context of environment. By examining thoughts and distinctive behavior of societies which are formed on the different contexts of environment, minds of many researchers of geographical and anthropology fields has led to this view that there is a significant relationship between environmental conditions, opinions and human activities. By adding human factor and his activities to natural environment, in other words, by starting interference of human beings in nature, geographical environment change to natural environment. Perhaps, the most obvious aspects of environmental (natural) effects on human were known as culture phenomenon; one that takes distinctive form and content in the different natural ranges. Affecting's "Iranian carpet" by the environment, as an art in use, a human phenomenon (from a geographical viewpoint) and one of physical manifestations of culture ( from the cultural viewpoint), could be examined based on two centerpieces: first, effect of these conditions on production processing dimensions (production facilities, production system, production time), second, shaping type of environmental conditions of one area to "forming/ aesthetic" and "technical/in practice" dimensions of carpet of that area. Also, another topic of this paper was lack of affecting many areas by the determinism conditions of environment for manufacturing products such as carpet; when we discussed "possibilism" and "determinism" schools, and interactions and relationships between human and the natural environment, we found the main difference in the power of one and other inability. Accordingly, "determinism" schools emphasized the human inability when encounter with the nature, they said that all thoughts and practices of human are influenced by the environmental determinism. On the other hand, possibilism supporters believed that the human triumph over this confrontation and by his authority overcomes any circumstances and environmental factors have no effect on his power. In a phenomenon like the carpet, one could conform these two approaches to definitions of "style" and "school" in this field. As a result, in the areas where become prevalent carpet-weaving styles, environmental and geographical circumstances has a more highlighted effect on the conditions of the production process and quality of the final product; but in the areas where producers styles or technique of carpet designers are applied, it is more evident the human hegemony over the environment.

\section{REFERENCES}

Badri Far, Mansour. (2011), human geography of Iran, Tehran, Payame Noor University Publications Behforouz, Fatemeh. (1995), The dominant fields in human geography, Tehran, Publications of Tehran University

Submit Date: 01.05.2016, Acceptance Date: 20.06.2016, DOI NO: 10.7456/10603100/003

Copyright $($ The Turkish Online Journal of Design, Art and Communication 
Beyg Mohammadi, Hassan. (2002), The role of geographical factors in the emergence of first centers of governments in the Iranian plateau, articles abstract of the first National Conference on Iranian Studies, Tehran, Publications of Iranology Foundation Ebrahimi, Morteza. (2014), Investigation of necessity of interdisciplinary studies in the humanities, Interdisciplinary studies in the humanities, 6(2), 19-32.

Fakouhi, Nasser. (2008), Anthropology portions, Tehran, Ney publication

Fakouhi, Naser. (2013), Principles of Anthropology, Tehran, Ney publication

Faramarz Gharamaleki, Ahad. (2000), the methodology of religious studies, Mashhad, Razavi

University of Islamic Sciences

Farid, Yadu'llah. (1991), the process of thought in the field of human geography, Tabriz, publications of Tabriz University

Hafeznia, Mohammad Reza. (1996), thoughts of Ibn Khaldun in the field of geographic factors effect on human, Quarterly Journal of Modarres, Second period, First number.

Hosouri, Ali. (2002), Principles of traditional design in Iran, Tehran, Cheshmeh Publication Daryayi, Nazila. (2008), Aesthetics in Iranian handmade carpet, Tehran, National center of Iranian carpet

Hangldin, Armen. (1996), Iranian carpets (materials and tools, backgrounds of designs ...), Tehran, Publications of the cultural center

Johnson, Ronald. (2000), The problem of geographical locations, Tehran, Publications of Ministry of Foreign Affairs

Jordan, Terry \& Auster Rowntree. (2001), An introduction to the Cultural Geography, Tehran, Publications of research center of Culture, Art and Communication

Kavyani Rad, Murad. (2004), geographical foundations of Iran culture, Quarterly Journal of Strategic Studies, Eighth year, Serial No. 27

Kern, S, (1983) the Culture of Time and Space. Cambridge University Press. Cambridge.Plumwood. Val (2002). "Environmental Culture" in Human Geography. Vol 12, No4. Pp. 22-31

Momtahan, Hossein Ali. (2535), the survival secret of civilization and culture of Iran, Tehran, Publications of Iran National University

Rostami, Fereshteh. (2015), Comparative-interdisciplinary investigation of printing $\&$ publishing the story books of Daneshvar Simin and Soleimani Bilqis, Interdisciplinary studies in the humanities, 7 (3), 63-92

Saver, Roger. (2004), A Preliminary Study of Iranian carpet, From history and art of carpet weaving in Iran (According to Iranica Encyclopedia), Under the supervision of Ehsan Yar Shater, Translated by: Lali Khamseh, Tehran, Niloufar publications

Shakuie, Hussein. (1996), new ideas in the philosophy of geography, Tehran, Gita Shenasi Publications Shahedani Sadeghi, Mehdi \& Esmaeili, Mohammad Reza. (2011), the application of integrated approaches for explaining the cognitive requirements of Islam in the theorization of Islamic economy. Interdisciplinary studies in the humanities. 2 (7),117-140

Semple. C. Ellen (1997). Influences Geographic Environment. In human Geography. Edited by J. Agnew, D, N, Livingstone and A, Rogers. Blackwell. Pp. 252-267

Zarghami, Ismail and Behrouz, Seyed Mohammad. (2015), the role and concept of space in recreating the architectural theory and social sciences, interdisciplinary studies in the humanities. 2 (7), 81-99 Zhouleh, Tooraj. (2013), intellectual substructures and theoretical principles of knowledge of carpet study, Tehran, Barg e Nou (Yasavoli) 